\title{
An analysis of perioperative hidden blood loss in femoral intertrochanteric fractures: bone density is an important influencing factor
}

Haidong Cui ${ }^{1 \dagger}$, Kai Chen ${ }^{1 \dagger}$, Shujun Lv ${ }^{1}$, Chaoqun Yuan ${ }^{1}$ and Youhua Wang ${ }^{2 *}$

\begin{abstract}
Background: To explore the influencing factors of perioperative hidden blood loss in intertrochanteric fractures. Method: We undertook a retrospective analysis from January 2016 to October 2019. Clinical data of 118 patients with intertrochanteric fractures were included. Hidden blood loss was calculated from the haematocrit changes before and after surgery using the Gross equation based on height, weight, and haematocrit (HCT) changes before and after surgery. Patients' gender, age, presence of underlying diseases, fracture types, anaesthesia methods, time from injury to surgery, administration of antiplatelet drugs within 6 months before surgery, use of anticoagulant drugs after surgery, and bone density were statistically analysed. Factors having an effect on hidden blood loss were screened out. Then, hidden blood loss was used as the dependent variable, and each influencing factor was used in turn as the independent variable. Multivariate linear regression analysis was employed to analyse the related risk factors that affect hidden blood loss during the perioperative period of patients with intertrochanteric fractures.

Result: The apparent blood loss during the operation was $203.81 \pm 105.51 \mathrm{ml}$, and the hidden blood loss was $517.55 \pm 191.47 \mathrm{ml}$. There were significant differences in the hidden blood loss of patients with different fracture types (stable vs unstable), anaesthesia methods (general anaesthesia vs intraspinal anaesthesia), antiplatelet or postoperative anticoagulant drugs, and bone densities $(P<0.05)$. 05). Multiple linear regression analysis showed that internal fixation, age, fracture type, anaesthesia method, anticoagulant application, and bone density were related risk factors that affected hidden blood loss during the surgical treatment of intertrochanteric fractures.

(Continued on next page)
\end{abstract}

\footnotetext{
* Correspondence: wyhntdx@163.com

${ }^{\dagger}$ Kai Chen and Haidong Cui contributed equally to the work as co-first authors.

${ }^{2}$ Department of Orthopaedic Surgery, Affiliated Hospital of Nantong University, Xisi Road 20, Nantong 226001, Jiangsu, China

Full list of author information is available at the end of the article
}

C C The Author(s). 2021 Open Access This article is licensed under a Creative Commons Attribution 4.0 International License, which permits use, sharing, adaptation, distribution and reproduction in any medium or format, as long as you give appropriate credit to the original author(s) and the source, provide a link to the Creative Commons licence, and indicate if changes were made. The images or other third party material in this article are included in the article's Creative Commons licence, unless indicated otherwise in a credit line to the material. If material is not included in the article's Creative Commons licence and your intended use is not permitted by statutory regulation or exceeds the permitted use, you will need to obtain permission directly from the copyright holder. To view a copy of this licence, visit http://creativecommons.org/licenses/by/4.0/ The Creative Commons Public Domain Dedication waiver (http://creativecommons.org/publicdomain/zero/1.0/) applies to the data made available in this article, unless otherwise stated in a credit line to the data. 


\begin{abstract}
(Continued from previous page)
Conclusion: Hidden blood loss is the main cause of perioperative blood loss in intertrochanteric fractures, and the risk factors for hidden blood loss include internal fixation, fracture type (e.g., unstable), anaesthesia (e.g., intraspinal), and use of anticoagulant drugs. Specifically, we found that low bone density was a risk factor for hidden blood loss. It is not reliable to use apparent blood loss as the basis for fluid replacement and transfusion. We must fully consider the existence of hidden blood loss and intervene as soon as possible to prevent complications.
\end{abstract}

Level of evidence: III

Keywords: Intertrochanteric fracture, Hidden blood loss, Influencing factors, Bone density

\section{Background}

As the population ages, the incidence of femoral intertrochanteric fracture is increasing. Indeed, intertrochanteric fracture has become the most prevalent type of hip fracture among elderly individuals [1]. At present, surgery is the most common treatment for femoral intertrochanteric fracture [2]. During surgery, loss of blood is inevitable. In the past, dominant blood loss during operations has received great attention in clinical practice. However, the existence of perioperative hidden blood loss has been neglected frequently. However, the haemoglobin level of patients after surgery has a great influence on hidden blood loss [3]. At present, an increasing number of studies have focused on the influencing factors of hidden blood loss perioperatively. However, most of these reports are not comprehensive, especially with respect to the relationship between bone density and hidden blood loss. Therefore, we carried out this retrospective study to explore the influencing factors of hidden blood loss perioperatively and thereby provide a reference for clinical treatment.

\section{Methods}

\section{General information}

From January 2016 to October 2019, 118 patients with intertrochanteric fractures treated at Hai'an People's Hospital were included. The inclusion criteria were as follows: (1) fresh intertrochanteric fractures without multiple fractures or pathological fractures; (2) no previous blood disease history and normal coagulative function on the preoperative test; and (3) routine blood examination performed preoperatively and on days 2 and 3 postoperatively. A total of 118 patients, 57 males and 61 females, met the inclusion criteria. The age distribution of patients was as follows: 31 patients $<60$ years old and 87 patients $\geq 60$ years old. There were 58 stable fractures (Evans type I, II) and 60 unstable fractures (Evans type III, IV) [4]. Anaesthesia method: Fortyseven patients received general anaesthesia, and 71 patients received intraspinal anaesthesia. Sixty-four patients were treated with anticoagulant drugs. There were 57 patients with hypertension and 60 patients with diabetes. All patients underwent dual energy X-ray absorptiometry to test their bone density before surgery. During the bone density subgroup analysis, the included patients were divided into three groups according to the criteria recommended by the WHO for the diagnosis of osteoporosis: the group with normal bone density (T-value $>-1.0)$, the osteopenia group $(-2.5<\mathrm{T}$-value $<-1.0)$, and the osteoporosis group (T-value $<-2.5)$.

\section{Detection index}

Hidden blood loss $=$ total blood loss - apparent blood loss + transfusion. Patient blood volume $(\mathrm{PBV})=\mathrm{K} 1 \times$ height $(\mathrm{h})^{3}+\mathrm{K} 2 \times$ weight $(\mathrm{kg})+\mathrm{K} 3$. For men, $\mathrm{K} 1, \mathrm{~K} 2$ and K3 were $0.3669,0.03219$ and 0.6041 , respectively. For women, K1, K2 and K3 were 0.3561, 0.03308, and 0.1833 , respectively [5]. Total red blood cell (RBC) loss $=$ preoperative blood volume $(\mathrm{PBV}) \times($ preoperative HCT- postoperative HCT). Total theoretical blood loss $=$ total $\mathrm{RBC}$ loss/preoperative HCT. Actual perioperative blood loss $=$ hidden blood loss + apparent blood loss. Apparent blood loss = intraoperative blood loss + volume of drainage. For patients requiring blood transfusions, $1 \mu \mathrm{l}$ of concentrated RBC suspension is equivalent to $200 \mathrm{ml}$ of standard RBC volume.

\section{Statistical analysis methods}

SPSS 13.0 software was used for analysis. A statistical analysis was carried out on the variables of patient gender, age, weight, bone density, underlying diseases (hypertension, diabetes), fracture type, internal fixation method, anaesthesia method, use of anticoagulant medication, etc. The risk factors were analysed by multiple linear regression analysis, with hidden blood loss as the dependent variable and influencing factors as the independent variables. $P<0.05$ was considered statistically significant.

\section{Results}

\section{Blood loss}

The intraoperative apparent blood loss was $203.81 \pm$ $105.51 \mathrm{ml}$, while the hidden blood loss was $517.55 \pm$ $191.47 \mathrm{ml}$. 
Comparison of hidden blood loss under different factors The perioperative hidden blood loss of patients with femoral intertrochanteric unstable fractures was significantly greater than that of patients with stable fractures $(P<0.05)$. The hidden blood loss of patients using general anaesthesia was significantly greater than that of patients with spinal canal anaesthesia $(P$ $<0.05$ ). The hidden blood loss of patients using anticoagulant drugs was also significantly greater than that of the non-users $(P<0.05)$. The hidden blood loss of patients equal to or older than 60 years old was significantly greater than that of patients younger than 60 years $(P<0.05)$. Specifically, patients with osteoporosis had significantly greater hidden blood loss than patients with normal bone density and osteopenia $(P<0.05)$ (Table 1$)$.

\section{Analysis of risk factors affecting hidden blood loss}

Multiple linear regression analysis was conducted with hidden blood loss as the dependent variable and influencing factors as the independent variables. The results showed that fracture type, anaesthesia mode, use of anticoagulant drugs, age and bone mineral density affected the perioperative hidden blood loss of patients with intertrochanteric fractures $(P<0.05)$ (Table 2).

Table 1 Comparison of hidden blood loss under different factors $(X \pm s)$

\begin{tabular}{|c|c|c|c|c|}
\hline Variable & Number of cases & Hidden blood loss & $t / F$ & $\mathbf{P}$ \\
\hline \multicolumn{5}{|l|}{ Gender } \\
\hline Male & 57 & $529.28 \pm 193.17$ & & \\
\hline Female & 61 & $506.48 \pm 190.79$ & 0.648 & 0.518 \\
\hline \multicolumn{5}{|l|}{ Age (years) } \\
\hline$\geq 60$ & 87 & $531.49 \pm 188.37$ & & \\
\hline$<60$ & 31 & $413.98 \pm 188.98$ & 2.190 & 0.030 \\
\hline \multicolumn{5}{|l|}{ Time of the operation } \\
\hline \multirow[t]{2}{*}{$<3 \mathrm{~h}$} & 78 & $511.37 \pm 188.37$ & & \\
\hline & 40 & $529.58 \pm 200.87$ & -0.487 & 0.627 \\
\hline \multicolumn{5}{|l|}{ Fracture type } \\
\hline Stable & 58 & $437.97 \pm 164.04$ & & \\
\hline Unstable & 60 & $536.84 \pm 163.26$ & -3.059 & 0.003 \\
\hline \multicolumn{5}{|l|}{ Anaesthesia } \\
\hline General anaesthesia & 47 & $596.20 \pm 177.26$ & & \\
\hline Intraspinal anaesthesia & 71 & $465.48 \pm 183.64$ & -3.838 & 0.000 \\
\hline \multicolumn{5}{|l|}{ Hypertension } \\
\hline Yes & 60 & $530.90 \pm 194.70$ & & \\
\hline No & 58 & $503.74 \pm 188.75$ & 0.769 & 0.443 \\
\hline \multicolumn{5}{|l|}{ Diabetes } \\
\hline Yes & 57 & $527.35 \pm 202.12$ & & \\
\hline No & 61 & $508.39 \pm 182.16$ & 0.536 & 0.593 \\
\hline \multicolumn{5}{|l|}{ Bone mineral density } \\
\hline Normal & 23 & $391.43 \pm 145.44$ & & \\
\hline Osteopenia & 46 & $497.42 \pm 181.97$ & & \\
\hline Osteoporosis & 49 & $595.63 \pm 185.44$ & 10.895 & 0.000 \\
\hline \multicolumn{5}{|l|}{ Use of anticoagulants } \\
\hline Yes & 64 & $559.17 \pm 190.16$ & & \\
\hline No & 54 & $468.22 \pm 182.68$ & -2.635 & 0.010 \\
\hline \multicolumn{5}{|l|}{ BMl } \\
\hline$\geq 28$ & 46 & $500.39 \pm 178.38$ & & \\
\hline$<28$ & 72 & $528.51 \pm 199.83$ & -0.777 & 0.439 \\
\hline
\end{tabular}


Table 2 Analysis of the risk factors affecting hidden blood loss

\begin{tabular}{|c|c|c|c|c|c|}
\hline Affecting Factors & Unstandardized Coefficients & Standard Error & Standardized Coefficients & $t$ & $\mathbf{P}$ \\
\hline Gender & 0.029 & 0.021 & 0.027 & 1.380 & 0.170 \\
\hline Age & 0.044 & 0.015 & 0.058 & 1.958 & 0.034 \\
\hline Time of the operation & -0.476 & 0.501 & -0.059 & -0.951 & 0.344 \\
\hline Fracture type & 1.794 & 0.194 & 0.427 & 9.242 & 0.000 \\
\hline Anaesthesia & 0.633 & 0.024 & 0.493 & 25.938 & 0.000 \\
\hline Hypertension & 0.002 & 0.220 & 0.000 & 0.010 & 0.992 \\
\hline Diabetes & 0.023 & 0.055 & 0.014 & 0.427 & 0.670 \\
\hline Bone mineral density & -0.622 & 0.032 & -0.482 & -19.537 & 0.000 \\
\hline Use of anticoagulants & -0.014 & 0.004 & -0.059 & -3.212 & 0.002 \\
\hline BMl & 0.001 & 0.010 & 0.002 & 0.099 & 0.922 \\
\hline
\end{tabular}

\section{Discussion}

Femur intertrochanteric fractures have a high incidence in the elderly population, and most of these fractures are comminuted. Displacement is a factor negatively affecting the outcome of intertrochanteric fractures [6]. Currently, surgery is the preferred treatment method for intertrochanteric fractures, with satisfactory curative effects and low complication rates [6]. There are mainly two kinds of surgical approaches: extramedullary fixation and intramedullary fixation [7]. Intramedullary fixation is becoming the preferred method for the surgical treatment of intertrochanteric fractures. Regarding the outcomes and complications of femoral intertrochanteric fractures, the fracture type, blood loss, operation, level of irisin hormone and presence of a pseudoaneurysm are important influencing factors $[7,8]$.

Perioperative blood loss may lead to many complications and a poor prognosis [9]. Such loss also increases the incidence of infection and deep vein thrombosis. Moreover, the patient's mortality rate rises [9]. Therefore, it is important to identify the causes of perioperative blood loss. Hidden blood loss accounts for a high percentage of the total perioperative blood loss in patients with intertrochanteric fractures. If the presence of hidden blood loss is not considered, it will often lead to anaemia or low blood volume in patients. This will affect postoperative recovery and even cause serious consequences. At present, the biological mechanism of hidden blood loss has not been clearly studied. The existing studies report that the causes of hidden blood loss include the following aspects: 1) blood that enters the tissue or the joint cavity and thus no longer participates in the humoral circulation [10] and 2) RBC haemolysis caused by injury. Some stressful events that occur during the operation, such as trauma and anaesthesia, may lead to changes in the internal blood environment and subsequent RBC peroxidation damage. On the other hand, $\mathrm{RBC}$ damage during the process of autologous blood transfusion and other factors may cause haemolysis, thus making hidden blood loss more serious. 3) Gastrointestinal stress ulcers caused by trauma and surgery will also cause hidden blood loss.

In this study, factors affecting perioperative hidden blood loss in patients with intertrochanteric fractures were analysed. We found that unstable fractures, advanced age, osteoporosis and general anaesthesia were independent risk factors for increasing hidden blood loss. Kumar et al. observed significant differences in the amount of hidden blood loss in patients with different fracture types [11]. Some researchers found that the hidden blood loss in patients with Evans I and II type fractures was significantly lower than that in patients with III and IV type fractures. They also found that there was a relationship between mean platelet volume and reoperation occurrence [4]. The results of our study showed that the hidden blood loss in patients with unstable fractures was significantly higher than that in patients with stable fractures, which confirms present research. It seems that there is a certain correlation between fracture type and hidden blood loss [12-15]. Therefore, we should pay attention to reviewing patients' routine blood tests and take timely blood transfusions during treatment for complicated fracture types.

In our study, we found that the selection of anaesthesia, the use of anticoagulant drugs and age are also key factors affecting perioperative hidden blood loss. This may be related to the fact that the antifibrinolytic ability of patients under general anaesthesia is lower than that of patients under epidural anaesthesia [16]. During the treatment of lower limb surgery patients, a certain amount of anticoagulant medication will be used to prevent the formation of venous thrombosis. Thus, the amount of hidden blood loss will also increase. In terms of age, in patients with total hip replacement, researchers found that the amount of hidden blood loss in patients older than 70 years was significantly higher than that in patients younger than 70 years [17]. In our study, the amount of hidden blood loss was significantly higher 
in patients over 60 years old than in patients under 60 years old. The effect of gender on the amount of hidden blood loss is still controversial. Most researchers believe that there is no significant difference between male and female patients with intertrochanteric femur fracture [18]. The results of our study indicate that gender is not a risk factor for hidden blood loss, which is consistent with most reports. In addition, some researchers believe that there are significant differences in the amount of hidden blood loss between different internal fixators, such as proximal femoral nail antirotation and the dynamic hip screw $[19,20]$. Some investigators also undertook studies regarding the time of occurrence of hidden blood loss. They found that hidden blood loss occurred just after injury and ended on postoperative day $2[21,22]$.

At present, there are few reports on the effect of bone density on perioperative blood loss in patients with intertrochanteric fractures. In our study, we found significant differences in the amount of hidden blood loss between groups with different bone mineral densities. This may be because, in patients with low bone density, the bone trabeculae become thin, and some even fracture. Osteoporosis may cause enlargement of the bone marrow space; the appearance of micropores and cancellation of the bone cortex; and the enlargement of periosteal pores, cortical pores, and endosteum pores. As a result of the above changes, osteoporosis maight increase the amount of blood loss during the perioperative period. In addition, patients with osteoporosis are generally older, their body's self-regulation ability is weakened, and their vascular elasticity is poor, which can also increase the risk of hidden blood loss. We should assess the bone density of each patient before surgery according to the imaging examination and the patient's medical history.

The advantages of this study are that bone density is an important influencing factor. This might affect the clinical strategy for intertrochanteric bone fracture. For example, for osteoporosis patients, we should improve their bone density to avoid more hidden blood loss. The limitations of this study are as follows: the time span of each patient was different, and the standards for some influencing factors might be different. Other potential factors, such as American Society of Anesthesiologists (ASA) grade and other complications, were not included in the study. The cases were obtained from multiple doctors, and there might have been differences during surgery.

\section{Conclusion}

Hidden blood loss is the main cause of perioperative blood loss in intertrochanteric fractures. The risk factors for hidden blood loss include internal fixation, fracture type, anaesthesia, and use of anticoagulant drugs. Specifically, we found that bone density was a risk factor for hidden blood loss. It is not reliable to use apparent blood loss as the basis for fluid replacement and transfusion. We must fully consider the existence of hidden blood loss and intervene as soon as possible to prevent complications.

\section{Abbreviations}

HCT: Haematocrit; WHO: World Health Organization; PVB: Patient blood volume; RBC: Total red blood cell; BMI: Body Mass Index

Acknowledgements

We extend thanks to our patients.

\section{Authors' contributions}

HD C: Study design and manuscript writing; K C: Data extraction and analysis, manuscript writing; SJ L: Provision of the patient data; CQ Y: Data analysis; YH W: Study design and technical guidance. All authors have read and approved the manuscript.

\section{Funding}

Scientific Research Project of the Nantong Municipal Science and

Technology Bureau (MSZ19024). Scientific Research Project of the Nantong Health Bureau (QB2019013) (provided support for the literature search).

Availability of data and materials

Author Haidong Cui can provide original data upon reasonable request. His email is 2036126481@qq.com.

Ethics approval and consent to participate

Not applicable.

\section{Consent for publication}

Yes

\section{Competing interests}

We declare that there are no competing interests in this study. We have no financial and personal relationships with other people or organizations that can inappropriately influence our work.

\section{Author details}

'Department of Orthopaedic Surgery, Hai'an People's Hospital, Zhongba Road 17, Hai'an 226600, Jiangsu, China. ${ }^{2}$ Department of Orthopaedic Surgery, Affiliated Hospital of Nantong University, Xisi Road 20, Nantong 226001, Jiangsu, China.

Received: 16 April 2020 Accepted: 26 December 2020

Published online: 04 January 2021

References

1. Zhang Y, Shen J, Mao Z, Long A, Zhang L, Tang P. Risk factors of hidden blood loss in internal fixation of intertrochanteric fracture. Zhongguo Xiu Fu Chong Jian Wai Ke Za Zhi. 2014;28(5):610-4 Epub 2014/07/31. PubMed PMID: 25073283

2. Wang $W$, Zhai $S$, Han XP, et al. Comparative study of proximal femoral nail anti-rotation and dynamic hip screw in the unstable intertrochanteric fractures in the elderly. Zhonghua Yi Xue Za Zhi. 2018;98(5):357.

3. Jia $L$, Zhang $K$, Wang ZG, et al. Proximal femoral nail anti rotati on internal fixation in treating intertrochanteric femoral fractures of elderly subjects [J]. J Biol Regul Homeost Agents. 2017;31(2):329-34.

4. Serbest $\mathrm{S}$, Tiftikci U, Tosun HB, Kesgin E, Karatas M. Isolated posterior malleolus fracture: a rare injury mechanism. Pan Afr Med J. 2015;20:123. https://doi.org/10.11604/pamj.2015.20.123.6046 Epub 2015/06/23. PubMed PMID: 26097627; PubMed Central.

5. Yang X, Wu Q, Wang X. Investigation of perioperative hidden blood loss of unstable intertrochanteric fracture in the elderly treated with different intramedullary fixations. Injury. 2017:48(8):1848-52. https://doi.org/10.1016/j. injury.2017.06.017 
6. Gumustas S, Tosun HB, Isyar M, Serbest S, Oznam K, Bulut G. Femur neck fracture in young adults, is it really an urgent surgery indication: retrospective clinical study. Pan Afr Med J. 2018;30:112. Epub 2018/10/27. https://doi.org/10.11604/pamj.2018.30.112.13643.

7. Serbest $S$, Tiftikçi U, Tosun HB, Gümüştaş SA, Uludag A. Is there a relationship between fracture healing and mean platelet volume? Ther Clin Risk Manag. 2016;12:1095-9. https://doi.org/10.2147/tcrm.S108790.

8. Serbest $\mathrm{S}$, Tiftikci U, Tosun HB, Kisa U. The Irisin Hormone Profile and Expression in Human Bone Tissue in the Bone Healing Process in Patients. Med Sci Monit. 2017;23:4278-83. Epub 2017/09/05. https://doi.org/10.12659/ msm.906293.

9. Smith GH, Tsang J, Molyneux SG, White TO. The hidden blood loss after hip fracture. Injury. 2011;42(2):133-5. Epub 2010/03/20. https://doi.org/10.1016/j. injury.2010.02.015.

10. Li S, Xu C, Tong P, et al. Progress on peri-operative hidden blood loss after hip fracture [J]. China J Orthop Traumatol. 2014;27(10):882-6.

11. Kumar R, Singh RN, Singh BN. Comparative prospective study of proximal femoral nail and dynamic hip screw in treatment of intertrochanteric fracture femur [J]. J Clin Orthop Trauma. 2012;3(1):28-36.

12. Foss NB, Kehlet $\mathrm{H}$. Hidden blood loss after surgery for hip fracture. J Bone Joint Surg Br. 2006;88(8):1053-9. https://doi.org/10.1302/0301-620x.88b8. 17534 Epub 2006/08/01. PubMed PMID: 16877605.

13. Liu Y, Sun Y, Fan L, Hao J. Perioperative factors associated with hidden blood loss in intertrochanteric fracture patients. Musculoskelet Surg. 2017; 101(2):139-44. https://doi.org/10.1007/s12306-016-0447-7 Epub 2017/01/09. PubMed PMID: 28064380.

14. Guo WJ, Wang JQ, Zhang WJ, Wang WK, Xu D, Luo P. Hidden blood loss and its risk factors after hip hemiarthroplasty for displaced femoral neck fractures: a cross-sectional study. Clin Interv Aging. 2018;13:1639-45. https:// doi.org/10.2147/CIA.S174196 Epub 2018/09/22. PubMed PMID: 30237699; PubMed Central PMCID: PMCPMC6136912

15. Lin PH, Chien JT, Hung JP, Hong CK, Tsai TY, Yang CC. Unstable intertrochanteric fractures are associated with a greater hemoglobin drop during the perioperative period: a retrospective case control study. BMC Musculoskelet Disord. 2020;21(1):244. https://doi.org/10.1186/s12891-02003208-2 Epub 2020/04/16. PubMed PMID: 32293388; PubMed Central PMCI D: PMCPMC7158073.

16. Li S, Guo T, Zhao J, et al. Risk factors and prognosis of perioperative hidden blood loss in hip replacement patients [J]. J Clin Rehabil Tissue Eng Res. 2014;18(13):2006-11.

17. Ma KL, Wang X, Luan FJ, et al. Proximal femoral nails antirotation, gamma nails, and dynamic hip screws for fixation of intertrochanteric fractures of femur: a meta-analysis [J]. Orthop Traumatol Surg Res. 2014;100(8):859-66.

18. Smith GH, Tsang J, Molyneux SG, et al. The hidden blood loss after hip fracture [J]. Injury. 2011;42(2):133-5.

19. Yu W, Zhang X, Wu R, Zhu X, Hu J, Xu Y, et al. The visible and hidden blood loss of Asia proximal femoral nail anti-rotation and dynamic hip screw in the treatment of intertrochanteric fractures of elderly high- risk patients: a retrospective comparative study with a minimum 3 years of follow-up. BMC Musculoskelet Disord. 2016;17:269. Epub 2016/07/13. https://doi.org/10. 1186/s12891-016-1143-3.

20. Yu X, Zhang $H$, Zhang $X, X u R$, She $Y, Y u Z$, et al. Effects of the ratios of marrow cavity diameter to intramedullary nail diameter from different layers on blood loss during perioperative period for femoral intertrochanteric fractures. Medicine (Baltimore). 2019;98(37):e16936. Epub 2019/09/14. https://doi.org/10.1097/MD.0000000000016936.

21. Li B, Li J, Wang S, Liu L. Clinical analysis of peri-operative hidden blood loss of elderly patients with intertrochanteric fractures treated by unreamed proximal femoral nail anti-rotation. Sci Rep. 2018;8(1):3225. Epub 2018/02/ 21. https://doi.org/10.1038/s41598-018-21703-4.

22. Tian $\mathrm{S}$, Li H, Liu M, Zhang Y, Peng A. Dynamic analysis of perioperative hidden blood loss in intertrochanteric fractures. Clin Appl Thromb Hemost. 2019;25:1076029618823279. Epub 2019/02/26. https://doi.org/10.1177/ 1076029618823279.

\section{Publisher's Note}

Springer Nature remains neutral with regard to jurisdictional claims in published maps and institutional affiliations.

\section{Ready to submit your research? Choose BMC and benefit from:}

- fast, convenient online submission

- thorough peer review by experienced researchers in your field

- rapid publication on acceptance

- support for research data, including large and complex data types

- gold Open Access which fosters wider collaboration and increased citations

- maximum visibility for your research: over $100 \mathrm{M}$ website views per year

At BMC, research is always in progress.

Learn more biomedcentral.com/submissions 